\title{
Study of the expression levels of Hepatocyte nuclear factor 4 alpha and 3 beta in patients with different outcome of HBV infection
}

\author{
En-Qiang Chen ${ }^{1,2}$, Hui Sun ${ }^{1,2,3}$, Ping Feng ${ }^{1,2}$, Dao-Yin Gong ${ }^{4}$, Cong Liu ${ }^{1,2}$, Lang Bai ${ }^{1,2}$, Wen-Bing Yang ${ }^{1,2}$, \\ Xue-Zhong Lei ${ }^{1,2}$, Li-Yu Chen $^{1,2}$, Fei-Jun Huang ${ }^{4^{*}}$ and Hong Tang ${ }^{1,2^{*}}$
}

\begin{abstract}
Hepatocyte nuclear factors 4 alpha (HNF4 $\alpha$ ) and 3 beta (HNF3 $\beta$ ) are members of a group of liver-enriched transcription factors (LETFs) that play important roles in regulating the replication of hepatitis B virus (HBV) and liver inflammation. However, the relationship of the level of HNF $4 \alpha$ and HNF3 $\beta$ with the severity of HBV-infected liver diseases is unclear. In this study, liver tissue samples from different types of HBV patients were collected, and HNF $4 \alpha$ and HNF3 $\beta$ expression were detected by immunohistochemistry. The expression of HNF $4 \alpha$ was significant higher in patients with severe hepatitis $\mathrm{B}(\mathrm{SHB})$ than those with chronic hepatitis $\mathrm{B}(\mathrm{CHB})$ and liver cirrhosis $(\mathrm{LC})$ (both $P<0.05)$, but similar between patients with CHB and LC $(P>0.05)$. And the expression of HNF3 $\beta$ was similar among patients with CHB, LC and SHB ( $P>0.05$ for all pairwise comparison). This suggests that the expression level of HNF4 $\alpha$ was different in patients with different outcome of HBV infection, high expression level of HNF4 $\alpha$ may correlate with occurrence of SHB
\end{abstract}

Keywords: Hepatocyte nuclear factor-4 alpha, Hepatocyte nuclear factor-3 beta, Chronic hepatitis B, Severe hepatitis B, Liver cirrhosis, Immunohistochemistry

\section{Background}

Hepatitis B virus (HBV) infection is a serious global health problem, with 2 billion people infected worldwide [1], and it would lead to various clinical outcomes, ranging from an asymptomatic carrier state (inactive HBV carrier) to acute or chronic liver disease including chronic hepatitis B (CHB), severe hepatitis B (SHB), liver cirrhosis (LC) and hepatocellular carcinoma(HCC) [2]. Because of the lack of specific therapies, those patients are at high risk of mortality [3]. Currently, HBV infection has become the 10th cause of death worldwide, and approximately $15-40 \%$ of those patients with $\mathrm{CHB}$ will develop to end-stage liver disease including LC, SHB, or HCC [1].

\footnotetext{
* Correspondence: hfj60123@hotmail.com; htang6198@hotmail.com ${ }^{1}$ Center of Infectious Diseases, West China Hospital of Sichuan University, Chengdu 610041, Sichuan Province, People's Republic of China

${ }^{4}$ Department of Forensic Pathology, College of Basic medicine and Forensic medicine, Sichuan University, Chengdu 610041, Sichuan Province, People's Republic of China

Full list of author information is available at the end of the article
}

Outcomes of HBV infection are affected by both virus (such as: virus variation, virus protein, virus genotype, etc.) and host factors (such as: cellular immunity, cytokines, apoptosis, etc.) [4-8], and evidence have showed that viral replication is mainly correlated to the development or progression of diseases [2,4]. In fact, viral replication is not only regulated by host factors [9], but also can cause changes in the level and activity of host factors, which would result to severe hepatic damage due to cell dysfunction. Hepatic nuclear factors (HNFs) are a group of important host transcription factors that mainly reside in the liver and regulate numerous liver-expressed genes [10]. One of our previous work suggested that HNF4 $\alpha$ and HNF3 $\beta$ likely participated in HBV replication in patients with HBV infection, or that HBV replication may somehow influence the expression of hepatocyte nuclear factor 4alpha $(\mathrm{HNF} 4 \alpha)$ and 3 beta (HNF3 $\beta)$ in the liver [11]. Using cell culture and animal models, we also found that HNF4 $\alpha$ supports HBV replication in non-hepatic cells and HNF3 $\beta$ inhibits HBV replication [12]. And in recent years, 
the study of HNF in hepatitis B has become a research hotspot.

Recently some scholars using gene chip analyzed liver tissue samples of HBV infected patients, and they found that HBV infection could increase the transcription of HNF, which may be related to the occurrence of liver injury [13]. So we hypothesized the interaction of HNFs and HBV transcriptional regulation may play an important role in the pathogenesis of disease progression. However, it is still unclear whether the expression level of HNFs is correlated to the clinical outcomes of HBV infection. In present study, we studied the variation of HNF4 $\alpha$ and HNF3 $\beta$ expression in different types of hepatitis B, so as to investigate the correlation of HNFs expression and disease severity.

\section{Results}

Liver specimens from $19 \mathrm{HBV}$ infections with variety of clinical outcomes were studied, comprised of 6 patients with chronic hepatitis B (Group A), 6 patients with liver cirrhosis (Group B) and 7 patients with severe hepatitis B (Group C). The serum HBV DNA levels of those patients were ranged from 3 to $5 \log 10$ copies $/ \mathrm{mL}$, and its level was comparable among group A, B and C. Detailed characteristics of those patients were summarized in Table 1.

\section{Expression levels of HNF4 $\alpha$}

Expression of HNF4 $\alpha$ was detected in all 19 specimens, and the typical immunohistochemical images of HNF4 $\alpha$ in these groups were shown in Figure 1. The mean scores of HNF $4 \alpha$ were $4.29,4.75$ and 5.58 for specimens in group $\mathrm{A}, \mathrm{B}$, and $\mathrm{C}$, respectively (Table 2 ). Among those groups, $\mathrm{HNF} 4 \alpha$ scores was significant higher in group $\mathrm{C}$ as compared with either group A or B (Both $P<0.05$ ). Though higher scores were also observed in group $B$, the difference was not statistic significantly as compared with group A.

These data showed that HNF4 $\alpha$ expression was increased significantly in patients with SHB, and suggested that high expression of HNF4 $\alpha$ may correlate with occurrence of SHB

\section{Expression levels of $\mathrm{HNF} 3 \beta$}

Expression of HNF3 $\beta$ was detected in all 19 samples, and the typical immunohistochemical images of HNF3 $\beta$ in

Table 1 Demographic and clinical characteristics

\begin{tabular}{llll}
\hline & $\begin{array}{l}\text { CHB } \\
\text { (Group A) }\end{array}$ & $\begin{array}{l}\text { LC } \\
\text { (Group B) }\end{array}$ & $\begin{array}{l}\text { SHB } \\
\text { (Group C) }\end{array}$ \\
\hline Number & 6 & 6 & 7 \\
\hline Age, ys & 42.67 & 45.50 & 36.86 \\
\hline Male/Female & $6 / 0$ & $4 / 2$ & $4 / 3$ \\
\hline HBeAg(+)/HBeAg(-) & $0 / 6$ & $1 / 5$ & $0 / 7$ \\
\hline HBV DNA, log10 copies/mL & 3.60 & 3.55 & 3.29 \\
\hline
\end{tabular}

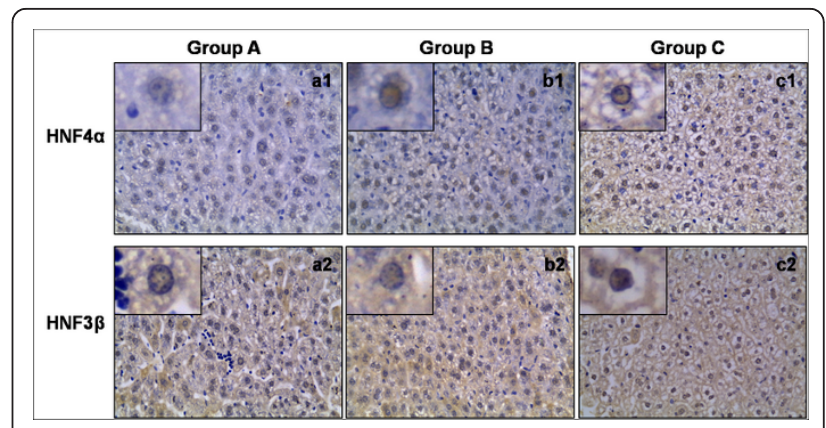

Figure 1 The expression of HNF4 $\alpha$ and HNF3ßin liver tissue of typical patients in three groups were shown. The scores of HNF $4 \alpha$ were higher in $\mathrm{c} 1$ as compared to $\mathrm{a} 1$ and $\mathrm{b} 1$; while the scores of HNF3 were similar among a2, b2 and c2.

these groups were shown in Figure 1. The mean scores of HNF3 $\beta$ were 2.71, 2.33 and 2.50 for specimens in group $\mathrm{A}, \mathrm{B}$, and $\mathrm{C}$, respectively (Table 3 ). Though more scores were observed in group $\mathrm{A}$, but the difference was not significant as compared with either group B or C. And the difference of score between group $B$ and $C$ was also not significant.

These data showed HNF3 $\beta$ expression was similar between different groups, and suggested that the expression of HNF3 $\beta$ may not correlate with clinical outcomes of HBV infections.

\section{Discussion}

Current study reported that abnormal expression of hostrelated genes in hepatitis B patients played important roles in the occurrence, development and prognosis of liver damage [6], and those host-related genes mainly were apoptosis and inflammation-associated genes [14-16]. Recently some scholars using gene chip analyzed liver tissue samples of HBV infected patients, and they found that HBV infection increased the transcription of many genes such as HNF4, retinoid X receptor and peroxisome proliferator-activated receptors (RXR/PPARs) and CCAAT/enhancer binding protein (C/EBP), and so

\section{Table 2 Scores of the expression levels of HNF4 $\alpha$}

\begin{tabular}{llll}
\hline & CHB (Group A) & LC (Group B) & SHB(Group C) \\
\hline Pat.1 & 2.5 & 4.5 & 6.0 \\
\hline Pat.2 & 4.5 & 5.0 & 6.0 \\
\hline Pat.3 & 5.0 & 5.0 & 6.0 \\
\hline Pat.4 & 4.5 & 5.0 & 6.0 \\
\hline Pat.5 & 4.0 & 4.5 & 4.5 \\
\hline Pat.6 & 5.0 & 4.5 & 5.0 \\
\hline Pat.7 & 4.5 & - & - \\
\hline Mean & $4.29^{\mathbf{\Delta}}$ & $4.75^{\Delta}$ & $5.58^{\Delta \Delta}$ \\
\hline
\end{tabular}

The symbol "\$" and " $\Delta$ " indicated significant difference between two groups $(p<0.05)$ 
Table 3 Scores of the expression levels of HNF3 $\beta$

\begin{tabular}{llll}
\hline & CHB (Group A) & LC (Group B) & SHB (Group C) \\
\hline Pat.1 & 2.5 & 1.5 & 3.0 \\
\hline Pat.2 & 2.0 & 3.0 & 3.0 \\
\hline Pat.3 & 2.0 & 1.0 & 1.5 \\
\hline Pat.4 & 4.5 & 0.5 & 1.5 \\
\hline Pat.5 & 3.0 & 5.5 & 1.0 \\
\hline Pat.6 & 3.0 & 2.5 & 1.0 \\
\hline Pat.7 & 2.0 & - & - \\
\hline Mean & 2.71 & 2.33 & 2.50 \\
\hline
\end{tabular}

on [13may correlate with disease severity of HBV infections. In contrast, HNF3 $\beta$ expression was similar among patients with different outcome of HBV infection, and it suggested HNF3 $\beta$ expression was not associated with disease severity caused by HBV, though our previous work showed HNF3 $\beta$ could inhibit HBV replication [was higher in liver tissue of patients with SHB, while the expression of HNF3 $\beta$ was similar among liver tissue of patients with different clinical outcomes, and our findings indicated that the expression level of HNF4 $\alpha$ and HNF3 $\beta$ in different HBV infections, and we found that the expression of HNF4 $\alpha$ ], which suggested the high expression of those gene may be related to the occurrence of liver injury caused by HBV. In present study, we observed the expression of HNF4 $\alpha[17,18]$.

HNFs are a class of protein molecules that mainly exist in liver and regulate liver-specific gene expression at transcriptional level, and HNF4 $\alpha$ is one of the most important regulatory factors of HNFs [10]. It has been reported that the over-expression of fibrinogen-like protein $2(\mathrm{fgl} 2)$ is correlated with occurrence of SHB, and the gene promoter of fgl 2 would be combined and activated by HNF4 $\alpha$, and it suggested that HNF4 $\alpha$ may play an important role in the occurrence of SHB [19]. Recently, we inhibited the expression of HNF4 $\alpha$ in mice with acute liver failure induced by lipopolysaccharide and D-Galactosamine, and we found that the liver damage of mice with LF was alleviated and mortality rate was significant decreased (unpublished data). The findings from experimental data also indicated that the over-expression of HNF4 $\alpha$ was an important factor for the occurrence of liver failure, which was consistent with the findings observed in liver tissue samples of patients with SHB in present study.

It has reported that HNF could bind and activate the four promoters of HBV genome, which is important for the regulation of transcription and replication of $\mathrm{HBV}$ [20]. So it is reasonable to infer that the correlation of over-expression of HNF4 $\alpha$ with severe hepatitis B may associate with its effect on HBV. We previously analyzed the incidence of mutations in HBV precore/basal core promoter $(\mathrm{BCP})$ in patients with $\mathrm{SHB}$, and found combined mutation of A1762T + G1764A (TA mutation) in HBV precore/BCP region might be related to the aggravation of chronic HBV infection(unpublished data), because of enhanced transcription and replication capacity of HBV [20]. Interesting, evidence showed that the binding site of $\mathrm{HNF} 4 \alpha$ on $\mathrm{HBV}$ also located in $\mathrm{HBV}$ precore/BCP region, so TA mutation in this region may affect HNF4 $\alpha$ on regulation of HBV transcription and replication [20]. In fact, the results from non-liver derived cell lines and HBV replication mouse model (with/without HNF4 $\alpha$ inhibition) had confirmed that HNF4 $\alpha$ supported high replication level of TA mutation, [20] which may contribute to the aggravation of hepatitis $\mathrm{B}$. Considering the positive correlation between HNF4 $\alpha$ expression and HBV replication in liver tissue of IHBV infections, and avoiding the interference of HBV DNA level on HNF4 $\alpha$ expression, only patients with serum HBV DNA less than $5 \log 10$ copies/ $\mathrm{mL}$ were included, and the mean level of HBV DNA was comparable between each group in this study. Thus, we believe our result is a credible finding.

In summary, our results suggested that the expression level of HNF4 $\alpha$ was different in patients with different outcome of HBV infection, and high expression level of HNF4 $\alpha$ may correlate with occurrence of SHB.

\section{Materials and methods \\ Study population}

A total of 19 liver tissue samples from 19 patients were obtained from Hepatobiliary Surgery Department and Center of Infectious Diseases, West China Hospital of Sichuan University, between 2007 and 2008. The clinical outcomes of those samples were consisted of $\mathrm{CHB}$ (group A, $\mathrm{n}=6$ ), LC (group B, $\mathrm{n}=6$ ) and SHB (group C, $\mathrm{n}=7)$.

All patients were positive for hepatitis B surface antigen ( $\mathrm{HBsAg}$ ) for at least 6 months, were without coinfection of human immune-deficiency virus (HIV) and other hepatitis viruses(hepatitis $\mathrm{A}, \mathrm{C}$ and $\mathrm{E}$ virus), and were without auto-immune hepatitis, drug-induced hepatitis, and liver damages caused by other etiologies.

The study protocol was conformed to the ethical guidelines of the 1975 Declaration of Helsinki.

\section{Preparation of integrated tissue slice slides}

Two different types of liver tissue specimens were obtained: wedge and needle biopsy specimens. The wedge specimens $\left(2 \times 2 \times 2 \mathrm{~cm}^{3}\right)$ were taken during open surgery, and needle biopsy specimens were obtained by a biopsy needle under ultrasound guidance. Liver specimens were fixed in $10 \%$ formalin for 24 to $48 \mathrm{~h}$ and embedded in paraffin.

For wedge specimens, a blank paraffin block was prepared and used as the recipient for the tissue samples, and a $2 \mathrm{~mm}$ punch needle was used to punch the donor 
paraffin block to transfer donor cores into blank recipient blocks at a defined region according to the marker made on blank paraffin block in advance. After all individual specimens were integrated on a single paraffin block, the integrated tissue was sectioned at a slice thickness of $4 \mathrm{~mm}$. Sections were stretched in a $40^{\circ} \mathrm{C}$ water bath, mounted a glass slides, and dried at $60^{\circ} \mathrm{C}$ for $2 \mathrm{~h}$.

For needle biopsy specimens, paraffin-embedded tissue was sectioned at a slice thickness of $4 \mathrm{um}$. And all sections were stretched in a $40^{\circ} \mathrm{C}$ water bath and mounted a glass slides at a defined region according to the marker made on the slide in advance. As a result, all tissue slices were integrated on a single slide.

\section{Detection of HNF4 $\alpha$ and HNF3 $\beta$ in liver tissue specimen by immunohistochemistry}

In this study, immunohistochemistry was used to detect expression levels of HNF4 $\alpha$ and HNF3 $\beta$ in liver tissue specimens. Paraffin sections were deparaffinized, rehydrated and incubated with $30 \mathrm{ml} / \mathrm{L} \mathrm{H}_{2} \mathrm{O}_{2}$ at $37^{\circ} \mathrm{C}$ for $15 \mathrm{~min}$. Antigen retrieval was achieved using Supersonic wave repair for $30 \mathrm{sec}$ (for detection of HNF4 $\alpha$ ) or microwave repair for 3 times plus Supersonic wave repair for $30 \mathrm{sec}$ (for detection of HNF3 $\beta$ ). Incubation with primary antibodies was performed at $37^{\circ} \mathrm{C}$ for $1 \mathrm{~h}$ and $4^{\circ} \mathrm{C}$ overnight, followed by three washes with phosphate-buffered saline (PBS). The primary antibodies used to detect the expression of HNF4 $\alpha$ and HNF3 $\beta$ were goat anti-human HNF4 $\alpha$ polyclonal antibody (1:50 diluted) (Santa Cruz, USA), and goat anti-human HNF3 $\beta$ polyclonal antibody (1:30 diluted) (Santa Cruz, USA), respectively. All sections were then incubated with biotin-labeled secondary antibodies including rabbit anti-goat IgG. After washing 3 times with $\mathrm{PBS}$, the immune complexes in the specimens were detected using DAB Substrate Kit (Wuhanboster Biological Technology, China) according to the manufacture's instructions. The slides were then counterstained with hematoxylin before being mounted.

\section{Immunohistochemical scoring criteria}

The immunohistochemical results of integrated tissue slice slides were read independently by two pathologists who had no prior knowledge of the experimental procedures. The percentage of positive cells and the positive staining intensity were checked and scored using the Axiotis score standard by observation of 5 randomly chosen fields at 400-fold magnification. Sections detected by immunohistochemistry were stained with DAB and conterstained with hematoxylin, and positive signals were manifested as yellow, brown, or tan staining. The scoring criteria for the proportion of positive cells were: $0=0 \%-10 \%$ positive cells; $1=11 \%-25 \%$ positive cells; $2=26 \%-50 \%$ positive cells; $3=51 \%-75 \%$ positive cells; $4=76 \%-100 \%$ positive cells. The scoring criteria for staining intensity in positive cells were: $0=$ no color, $1=$ yellow, $2=$ brown, $3=\tan$. The sum of the scores for proportion of positive cells and staining intensity was the final score for the sample. If the film-reading results of the two pathologists were different for the same sample, we then used the mean of the scores to generate the final result.

\section{Statistical analysis}

The scores of HNF4 $\alpha$ and HNF3 $\beta$ in specimens in each group were presented as mean, and data were analyzed using the SPSS version 13.0 software package (SPSS, Inc., Chicago, IL). Tests of significance were 2-tailed, with significance being indicated by a $P$-value $<0.05$.

\section{Acknowledgements}

This work was partially supported by the National Natural Science Foundation of China (No. 30972622), National Basic Research Program of China (No. 2007CB512902), and National Science and Technology Major Project of China (No.2012ZX10002007, and No.2008ZX10002-006).

\section{Author details}

${ }^{1}$ Center of Infectious Diseases, West China Hospital of Sichuan University, Chengdu 610041, Sichuan Province, People's Republic of China. ${ }^{2}$ Division of Infectious Diseases, State Key Laboratory of Biotherapy, Sichuan University, Chengdu 610041, People's Republic of China. ${ }^{3}$ Department of Infectious Diseases, North Sichuan Medical College, Nanchong 637000, People's Republic of China. ${ }^{4}$ Department of Forensic Pathology, College of Basic medicine and Forensic medicine, Sichuan University, Chengdu 610041, Sichuan Province, People's Republic of China.

\section{Authors' contributions}

We thank Prof. X-HY from Hepatobiliary Surgery Department for providing wedge specimens to this study. All authors read and approved the final manuscript

\section{Competing interests}

The authors declare that they have no competing interests.

Received: 6 September 2011 Accepted: 18 January 2012 Published: 18 January 2012

\section{References}

1. Lavanchy D: Hepatitis B virus epidemiology, disease burden, treatment, and current and emerging prevention and control measures. J Viral Hepat 2004, 11:97-107.

2. Blum HE: Hepatitis B virus: significance of naturally occurring mutants. Intervirology 1993, 35:40-50.

3. Marcellin P, Pequignot F, Delarocque-Astagneau E, Zarski JP, Ganne N, Hillon P, Antona D, Bovet M, Mechain M, Asselah T, Desenclos JC, Jougla E: Mortality related to chronic hepatitis $B$ and chronic hepatitis $C$ in France: evidence for the role of HIV coinfection and alcohol consumption. J Hepatol 2008, 48:200-207.

4. Huang $Y$, Lok AS: Viral factors and outcomes of chronic HBV infection. Am J Gastroenterol 2011, 106:93-95.

5. Museru O, Franco-Paredes C: Epidemiology and clinical outcomes of hepatitis B virus infection among refugees seen at a U.S. travel medicine clinic: 2005-2008. Travel Med Infect Dis 2009, 7:171-174.

6. Pungpapong S, Kim WR, Poterucha JJ: Natural history of hepatitis B virus infection: an update for clinicians. Mayo Clin Proc 2007, 82:967-975.

7. Hui CK, Leung N, Yuen ST, Zhang HY, Leung KW, Lu L, Cheung SK, Wong WM, Lau GK: Natural history and disease progression in Chinese chronic hepatitis B patients in immune-tolerant phase. Hepatology 2007, 46:395-401. 
8. Pan CQ, Zhang JX: Natural History and Clinical Consequences of Hepatitis B Virus Infection. Int J Med Sci 2005, 2:36-40.

9. Tang H, Banks KE, Anderson AL, McLachlan A: Hepatitis B virus transcription and replication. Drug News Perspect 2001, 14:325-334.

10. Costa RH, Kalinichenko W, Holterman AX, Wang X: Transcription factors in liver development, differentiation, and regeneration. Hepatology 2003, 38:1331-1347.

11. Long Y, Chen E, Liu C, Huang F, Zhou T, He F, Liu L, Liu F, Tang H: The correlation of hepatocyte nuclear factor 4 alpha and 3 beta with hepatitis B virus replication in the liver of chronic hepatitis B patients. J Viral Hepat 2009, 16:537-546.

12. Tang $H$, McLachlan A: Transcriptional regulation of hepatitis B virus by nuclear hormone receptors is a critical determinant of viral tropism. Proc Natl Acad Sci USA 2001, 98:1841-1846.

13. Wang Z, Bishop EP, Burke PA: Expression profile analysis of the inflammatory response regulated by hepatocyte nuclear factor 4alpha. BMC Genomics 2011, 12:128.

14. Li X, Salisbury-Rowswell J, Murdock AD, Forse RA, Burke PA: Hepatocyte nuclear factor 4 response to injury involves a rapid decrease in DNA binding and transactivation via a JAK2 signal transduction pathway. Biochem J 2002, 368:203-211.

15. Liang X, Liu Y, Zhang Q, Gao L, Han L, Ma C, Zhang L, Chen YH, Sun W: Hepatitis B virus sensitizes hepatocytes to TRAlL-induced apoptosis through Bax. J Immunol 2007, 178:503-510.

16. Janssen HL, Higuchi H, Abdulkarim A, Gores GJ: Hepatitis B virus enhances tumor necrosis factor-related apoptosis-inducing ligand (TRAIL) cytotoxicity by increasing TRAIL-R1/death receptor 4 expression. J Hepatol 2003, 39:414-420.

17. Tang $H$, McLachlan A: Mechanisms of inhibition of nuclear hormone receptor-dependent hepatitis $B$ virus replication by hepatocyte nuclear factor 3beta. J Virol 2002, 76:8572-8581.

18. Banks KE, Anderson AL, Tang H, Hughes DE, Costa RH, McLachlan A: Hepatocyte nuclear factor 3beta inhibits hepatitis B virus replication in vivo. J Virol 2002, 76:12974-12980

19. Ning Q, Lakatoo S, Liu M, Yang W, Wang Z, Phillips MJ, Levy GA: Induction of prothrombinase fgl 2 by the nucleocapsid protein of virulent mouse hepatitis virus is dependent on host hepatic nuclear factor-4 alpha. J Biol Chem 2003, 278:15541-15549.

20. Tang H, Raney AK, McLachlan A: Replication of the wild type and a natural hepatitis $B$ virus nucleocapsid promoter variant is differentially regulated by nuclear hormone receptors in cell culture. J Virol 2001, 75:8937-8948.

doi:10.1186/1743-422X-9-23

Cite this article as: Chen et al: Study of the expression levels of Hepatocyte nuclear factor 4 alpha and 3 beta in patients with different outcome of HBV infection. Virology Journal 2012 9:23.

\section{Submit your next manuscript to BioMed Central and take full advantage of:}

- Convenient online submission

- Thorough peer review

- No space constraints or color figure charges

- Immediate publication on acceptance

- Inclusion in PubMed, CAS, Scopus and Google Scholar

- Research which is freely available for redistribution

Submit your manuscript at www.biomedcentral.com/submit
C Biomed Central 